\title{
Research on Optimization of Joint Reserves for Emergency Supplies in Shelters
}

\author{
Shaoqing Geng*, Hanping Hou \\ School of Economics and Management \\ Beijing Jiaotong University \\ Beijing, China \\ 18113040@bjtu.edu.cn \\ Mingli Yu, Tiantian Zhang \\ School of economics and management \\ Beijing Jiaotong University \\ Beijing, China \\ 17125513@bjtu.edu.cn
}

\author{
Jianliang Yang \\ School of economics and management \\ Beijing University of Chemical Technology \\ Beijing, China \\ yangjianliang6265@126.com
}

\author{
Jingyan Zou \\ Assistant Engineer \\ Space star technology co., LTD \\ Beijing, China \\ Lixueb2141@163.com
}

\begin{abstract}
Relief resource such as food, drinking water and other emergency living materials need to be updated regularly during a certain period of warranty. Therefore, this kind of emergency resource resene needs to consider both the daily management cost and the emergency supply guarantee. In order to study the joint of the physical reserve of emergency materials and agreement reserve, a hybrid integer programming model is established by selecting a supermarket around the shelter as a protocol supplier for a storage period of the shelter. In the case of limited investment in emergency management funds, the number of storage materials in the shelters and surrounding supermarkets is determined, and the Lingo software is used to solve the problem. Finally, the validity of the model is verified by an example.
\end{abstract}

Keywords-emergency living materials; joint reserves; shelters; mixed integer programming

\section{INTRODUCTION}

Emergency logistics under disasters are characterized by suddenness, uncertainty, weak economy and unconventionality. The Chinese government has established 24 central-level disaster relief materials reserves and multiple local reserves in consideration of regional characteristics and population distribution to deal with possible disasters [1-3]. In recent years, these reserves have played an important role in disasters, but there are also problems such as limited reserves and lacking of flexibility in materials supply. Therefore, the physical reserves and agreement storage of emergency supplies are necessary. Under the joint reserves model, the government reserve resources and enterprise resources are effectively combined to form a unified multi-supply entity, which is led and managed by the government, so that all supply entities can cooperate with each other after the disaster, saving daily material management costs and making maximize the level of material security. Under the conditions of meeting the government budget, determining the amount of government storage and the amount of agreement reserves and making the availability of emergency living materials large has become one of the key issues to be solved in the study of joint reserves.

The storage of living materials is a problem of "combination of peacetime and warfare." In recent years, some studies have begun to pay attention to the management of emergency living materials. Patersonabca $C$ stressed the importance of the preparation stage of disaster relief supplies, pointing out that emergency living materials are used frequently in the process of emergency handling, so that emergency management organizations and suppliers establish stable cooperative relations, sign long-term purchase agreements, and establish corresponding reserve centers to ensure the quality of disaster relief materials and improve the ability to provide emergency supplies [4]. Fiedrich F pointed out that the most demanding emergency supplies include water, medicines, food and so on, which should focus on procurement and reserves [5]. Wang proposed to establish a dynamic reserve mechanism for emergency materials, and build a model with cost and benefit as the objective function, which consumes the least amount of materials and maximizes efficiency. Although reasonable pre-set inventory can improve disaster relief capacity, it will bring capital occupation, inventory management and other issues, similar to the situation in China's national reserves [6].

Because of different disaster relief policies and social environment, countries around the world have different modes of emergency supply, and there are few studies related to the agreement supplier model. Balcik proposed that the dynamic planning model of supplier selection in the premise that the rescue organization and the supplier signed the emergency material reserve framework agreement. The supplier was responsible for directly delivering the emergency materials to the disaster area according to the number of agreements [7]. Zhang Zili and others have studied the issue of government subsidies to encourage enterprises to expand their production capacity reserves in response to emergencies, as well as the 
proportion of investment by governments and suppliers [8-10]. Ding Bin proposed that the government entrusted suppliers to store a certain amount of emergency supplies, reduce the operating costs of the government reserve and ensure the reserves [11-13]. At the same time, in order to solve the problem of site selection of emergency materials storage warehouse, Kunz N considered the problem of NGO's emergency warehouse location, and established a mixed integer linear model to solve the storage location of nonexpendable materials needed for the primary stage of rescue [14]. S. Duran takes an inventory cycle as the research background, assuming that multiple disaster conditions and types of disasters may occur, and using a typical disaster as an example to establish a mixed integer programming model to optimize the location of emergency warehouses [15].

In summary, scholars have seldom studied the emergency living material supply models under the multi-supply main mode, and most of them are supply cooperative organizations formed after the disaster. Based on the above research, this paper will establish a mixed integer programming model to study the storage capacity of the shelter and the agreement provider in the context of reserve entity diversification,.

\section{PROBLEM DESCRIPTION}

The shelter demand for living materials is given, and the demand is greater than the storage capacity of the shelter. It is known that the government allocates a certain amount of living materials to the shelters, and within a prescribed distance, comprehensively evaluates the availability of emergency materials according to the storage capacity and turnover of the supermarkets to be selected, and selects a certain number of agreement suppliers. Under the condition of meeting the government budget, the operating costs incurred by the agreement supermarket due to the reserve will be subsidized, and the storage capacity of each agreement supermarket and shelter will be determined, so that the availability of living materials in the emergency situation is the greatest.

Model symbol and variable definition description:

A: Government budget within a storage cycle;

$D_{i}$ : The demand of the shelter $i$ for an emergency living material, $i=1,2, \ldots, M$;

Cap $_{i}$ : Maximum capacity of shelter $i, i=1,2, \ldots, M$;

$a_{i}$ : The lowest proportion of storage in shelter $i$ accounting for storage capacity, $i=1,2, \ldots, M$;

$C_{i:}$ Unit storage management cost of shelter $i, i=1,2, \ldots, M$;

$\mathrm{Cap}_{j:}$ The maximum storage capacity of the agreement supermarket $j, j=1,2, \ldots, N$;

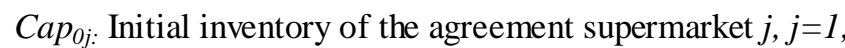
$2, \ldots, N$

$C_{j}$ : Unit storage running cost of agreement supermarket $j$, $j=1,2, \ldots, N$;

$\beta_{i}$ : The availability of materials stored in the shelter $i, i=1$, $2, \ldots, M$; $\beta_{j}$ : The availability of materials stored in the agreement supermarket $j, j=1,2, \ldots, N$;

$L_{i j}$ : The distance between the shelter $i$ and the supermarket $j$ to be selected, $i=1,2, \ldots, M, j=1,2, \ldots, N$;

$L_{s}$ : The prescribed distance between the shelter and the agreement supermarket;

$L_{i}$ : A collection of supermarkets to be selected around the shelter $i$ within the prescribed distance, $L_{i}=\left\{j \mid L_{i j} \leq L_{s}\right\}, i=1$, $2, \ldots, M$;

$Q_{i}$ : The storage capacity in shelter $i, i=1,2, \ldots, M$;

$\Delta Q_{j}$ : The reserve in supermarket $j, j=1,2, \ldots, N$;

$x_{i j}=1$, represents supermarket $i$ as an agreement provider for shelter $j ; 0$, otherwise, $i=1,2, \ldots, M, j=1,2, \ldots, N$;

Assume that an agreement supermarket order quantity is $Q$, the order period is $t$, no stock is not allowed, and the stocking time is short. After increasing the storage capacity $\Delta Q$, and the amount of the reserve is not lower than $\Delta Q$, the order period is unchanged, then the storage amount changes as shown in Fig. 1. It can be known that after the order quantity is increased, the first order quantity of the supermarket is $Q+\Delta Q$, and then the order quantity per cycle is still $Q$, so the increased cost is the first ordering cost and the future storage due to the multiorder $\Delta Q$. $Q$ and the increased cost of holding, inventory holding costs generally include operating costs, opportunity costs and risk costs, mainly considering the operating costs of the agreement suppliers.

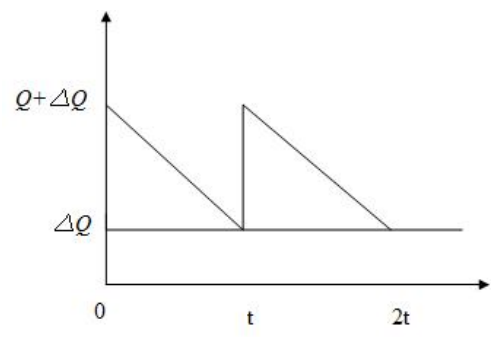

Fig. 1. Storage volume change

\section{MATHEMATICAL MODEI}

$$
\begin{gathered}
\max \sum_{i=1}^{M}\left(\sum_{j=1}^{N} X_{i j} \Delta Q_{j} \beta_{j}+Q_{i} \beta_{i}\right) \\
\text { s.t. } \quad \sum_{i=1}^{M} C_{i} Q_{i}+\sum_{j=1}^{N} \Delta Q_{j} C_{j} \leq A \\
\sum_{j \in L_{i}} x_{i j} \Delta Q_{j}+Q_{i} \geq D_{i} \quad i=1,2, \ldots, M \\
\sum_{i=1}^{M} x_{i j} D_{i} \geq \Delta Q_{j} \quad j=1,2, \ldots, N
\end{gathered}
$$




$$
\begin{gathered}
\sum_{i=1}^{M} x_{i j} \leq 1 \quad j=1,2, \ldots, N \\
a_{i} \operatorname{Cap}_{i} \leq Q_{i} \leq \operatorname{Cap}_{i} \quad i=1,2, \ldots, M \\
\Delta Q_{j}+\operatorname{Cap}_{0 j} \leq \operatorname{Cap}_{j} \quad j=1,2, \ldots, N \\
x_{i j} \in\{0,1\} \\
Q_{i}, \Delta Q_{j} \geq 0 \quad \text { integer }
\end{gathered}
$$

Objective (1) is to maximize the guarantee of life emergency materials in the joint reserve mode of the shelter and the agreement supermarket. Equation (2) is that the sum of the management cost of the shelter and the operating cost of the agreement supermarket within the government budget. Formula (3) is that the joint reserve must meet the need of the shelter. Formula (4) is the reserve of the supermarket to be selected as the agreement supplier. Equation (5) is that the supermarket to be selected can only be stored for one shelter at most; Equation (6) and (7) is the storage limit. Equation (8) is a $0-1$ variable constraint. Equation (9) is a non-negative integer constraint.

\section{EXPERIMENTAL STUDY}

A case is designed based on the background of certain types of emergency living materials for sudden disasters. Let there be $M=2$ shelters in this area, $N=8$ supermarkets to be selected; the information of each shelter is shown in Table 1, and the information of each candidate supermarket is shown in Table 2, the distance between the candidate supermarket and the shelter. $L_{i j}$ is shown in Table 3 . The distance between the refuge and the agreement supermarket is $L s=12 \mathrm{~km}$. In a storage period, the government budget $A=100$ units.

TABLE I. SHELTER INFORMATION

\begin{tabular}{|c|c|c|c|c|c|}
\hline $\begin{array}{c}\text { Shelter } \\
\text { number }\end{array}$ & Demand & Capacity & $\begin{array}{c}\text { Minimum } \\
\text { ratio }\end{array}$ & $\begin{array}{c}\text { Unit } \\
\text { management } \\
\text { cost }\end{array}$ & $\begin{array}{c}\text { Material } \\
\text { availability }\end{array}$ \\
\hline 1 & 40 & 30 & 0.2 & 3 & 0.95 \\
\hline 2 & 35 & 10 & 0.2 & 6 & 0.9 \\
\hline
\end{tabular}

TABLE II. CANDIDATE SUPERMARKET INFORMATION

\begin{tabular}{|c|c|c|c|c|}
\hline $\begin{array}{c}\text { Supermarket } \\
\text { number }\end{array}$ & Capacity & Initial stock & $\begin{array}{c}\text { Material } \\
\text { availability }\end{array}$ & $\begin{array}{c}\text { Unit operating } \\
\text { cost }\end{array}$ \\
\hline 1 & 15 & 3 & 0.1 & 0.6 \\
\hline 2 & 40 & 6 & 0.3 & 0.53 \\
\hline 3 & 20 & 5 & 0.2 & 0.56 \\
\hline 4 & 15 & 3 & 0.1 & 0.55 \\
\hline 5 & 22 & 16 & 0.2 & 0.6 \\
\hline 6 & 36 & 30 & 0.3 & 0.68 \\
\hline 7 & 12 & 6 & 0.1 & 0.67 \\
\hline 8 & 12 & 6 & 0.1 & 1 \\
\hline
\end{tabular}

TABLE III. DIST ANCE BETWEEN CANDIDATE SUPERMARKETS AND SHELTERS (UNIT: KM)

\begin{tabular}{|c|c|c|c|c|c|c|c|c|}
\hline $\begin{array}{c}\text { Supermarket } \\
\text { number }\end{array}$ & 1 & 2 & 3 & 4 & 5 & 6 & 7 & 8 \\
$\begin{array}{c}\text { Shelter } \\
\text { number }\end{array}$ & 5 & 1 & 10 & 10 & 19 & 10 & 2 & 11 \\
\hline 1 & 11 & 9 & 23 & 3 & 2 & 4 & 6 & 5 \\
\hline 2 & \multicolumn{1}{|c|}{}
\end{tabular}

The Lingo software solves the joint reserve model of emergency living materials. The final material reserve plan is shown in Table 4. The first two lines represent the joint reserve plan, and the last two lines represent the separate reserve plan of the shelter.

TABLE IV. DIST ANCE BETWEEN CANDIDATE SUPERMARKETS AND SHELTERS (UNIT: KM)

\begin{tabular}{|c|c|c|c|c|c|}
\hline $\begin{array}{c}\text { Shelter } \\
\text { number }\end{array}$ & Demand & $\begin{array}{c}\text { Self- } \\
\text { storage }\end{array}$ & $\begin{array}{c}\text { (Agreement } \\
\text { supermarket } \\
\text { number, storage } \\
\text { capacity) }\end{array}$ & $\begin{array}{c}\text { Target } \\
\text { value }\end{array}$ & cost \\
\hline 1 & 40 & 18 & $(3,15)(4,2)(6,6)$ & 34.9 & 100 \\
\hline 2 & 35 & 2 & $(2,34)(5,4)$ & & \multirow{2}{*}{29.35} \\
\hline 1 & 40 & 29 & $/$ & 100 \\
\hline
\end{tabular}

As can be seen from the table above, in the case of a certain government budget, relying solely on the shelter's own capabilities can not meet the reserve requirements of materials. When the agreement supermarkets store materials, the level of life emergency supplies is improved.

\section{Conclusion}

Considering the characteristics of disasters, the joint reserve of emergency living materials is used to improve the material security, reflecting the characteristics of "normally and urgently combined", and establishing a model of joint reserve of shelters and surrounding supermarkets under the condition of limited government budget. The Lingo software is used to solve the problem, and the effectiveness of the relevant models and methods is verified by an example.

In the issue of emergency materials reserve, it is necessary to conduct in-depth research into the production enterprises into the reserve system, and provide scientific and reasonable suggestions for supplementing and improving the relevant emergency materials reserve system.

\section{REFERENCES}

[1] Zhang Hong. Improvement of China's Emergency Material Reserve System [J]. China Administration, 2009 (3): 44-47.(In Chinese)

[2] Ding Lu, Yan Junli, Zhu Xiaoran, et al. Research on the Status Quo and Development Trend of Emergency Logistics for Emergency Disaster Rescue[J]. Journal of Institute of Disaster Prevention Science and Technology, 2018(2) .(In Chinese)

[3] Tian Xue, Niu Pengfei, Wang Chen. Analysis on the Status Quo and Countermeasures of China's Emergency Logistics Development[J]. Modern Business, 2017(27): 73-74. (In Chinese) 
[4] Patersonabca C. Inventory models with lateral transshipments: A review[J]. European Journal of Operational Research, 2011, 210(2): 125-136.

[5] Fiedrich F, Gehbauer F, Rickers U. Optimized resource allocation for emergency response after earthquake disasters[J]. Safety Science, 2000, 35(1):41-57.

[6] Wang X, Chen H, Wang K. Studies on Emergency Logistics Operation Model for Unexpected Events at Yangtze Chemical Industrial Park[C]// 2012 international symposium on safety science and engineering in china. 2012:353-358.

[7] Balcik B, Beamon B M, Krejci C C, et al. Coordination in humanitarian relief chains: Practices, challenges and opportunities[J]. International Journal of Production Economics, 2010, 126(1):22-34.

[8] Zhang Zili, Li Xiangyang, Wang Guisen. Research on Enterprise Selection of Emergency Materials Agreement Based on Production Capacity Reserve[J]. Operations Research and Management Science, 2009, 18(1): 146-150. (In Chinese)

[9] Zhang Zili. Research on production capacity reserve model for unconventional emergencies [D]. Harbin Institute of Technology, 2010. (In Chinese)
[10] Zhang Zili, Li Xiangyang, Zhang Ziqiong. Government and Enterprise Emergency Funding Planning Model Based on Common Reserves of Production Capacity[J]. Journal of Industrial Engineering and Engineering Management, 2011, 25(1): 56-61. (In Chinese)

[11] Ding Bin, Gui Bin. Emergency Material Inventory Strategy under Prepaid Conditions Based on Cooperative Game[J]. Operations Research and Management, 2011, 20(3): 60-65. (In Chinese)

[12] Ding Bin, Lei Xiu, Sun Lianlu. The Choice of Emergency Material Reserve Method and Cost Sharing Problem[J]. Journal of Beijing Institute of Technology(Social Science Edition), 2011, 13(6): 73-78. (In Chinese)

[13] Ding Bin, Zou Yueyue. EOQ Model of Emergency Materials Based on the Model of Govern ment-Enterprise Joint Reserve[J]. Journal of Dalian University of Technology(Social Science Edition), 2012, 33(1): 90-94. (In Chinese)

[14] Kunz N, Reiner G, Gold S. Investing in disaster management capabilities versus pre-positioning inventory: A new approach to disaster preparedness[J]. International Journal of Production Economics, 2014, 157(00):261-272.

[15] Duran S, Gutierrez M A, Keskinocak P. Pre-Positioning of Emergency Items for CARE International[J]. Interfaces, 2011, 41(3):223-237. 